\title{
PHYSICAL FOUNDATIONS OF RHENIUM-OSMIUM METHOD - A REVIEW
}

\author{
JÓZEF DĄBEK and STANISLAW HALAS \\ Mass Spectrometry Laboratory, Institute of Physics, Maria Curie-Sklodowska University, \\ Plac Marii Curie-Sktodowskiej 1, 20-031 Lublin, Poland
}

\begin{abstract}
A newly acquired mass spectrometer MI 1201 by the Mass Spectrometry Laboratory will be adapted to determine rhenium and osmium isotope concentrations using negative thermal ionization mass spectrometry (NTIMS). We describe the principle of the Re-Os dating technique and the thermal ionization phenomena which lead to high precision isotope analysis on NTIMS.
\end{abstract}

Keywords: Re-Os dating, negative ions, thermal ionization, mass spectrometry, ${ }^{187}$ Re decay

\section{INTRODUCTION}

The application of the radioactive decay in geochronology is nearly as old as the discovery of radioactivity. The discovery of the radioactivity of uranium and thorium which take place around the turn of the XX century was soon proposed by Rutherford to use this phenomenon to measure the ages of uranium-bearing minerals (Faure, 1986). The early methods of dating were founded on the accumulation of $\mathrm{He}$ and $\mathrm{Pb}$ as the decay products of uranium and thorium.

The Re-Os method of dating based on the beta decay of ${ }^{187} \mathrm{Re}$ to ${ }^{187} \mathrm{Os}$ (see Eq. 1.1) is a relatively new method.

${ }^{187} \mathrm{Re} \stackrel{\beta^{-}}{\longrightarrow}{ }^{187} \mathrm{Os}$

Rhenium (Re) was discovered by the German chemists Walter Noddack, Ida Tacke Noddack and Otto Berg in platinum ores and columbite (also called niobite) in 1925. Re was the last naturally occurring element with stable nuclei to be added to the periodic table. They also found this element in gadolinite and molybdenite. By processing $660 \mathrm{~kg}$ of molybdenite they were able to extract 1 gramm of rhenium in 1928. Rhenium has two naturally occuring isotopes, namely ${ }^{185} \mathrm{Re}$ and ${ }^{187} \mathrm{Re}$ whose abundances are $37.398 \pm 0.016 \%$ and $62.602 \pm 0.016 \%$, respectively. Natural radioactivity of isotope ${ }^{187} \operatorname{Re}$ (beta minus decay) was discovered and

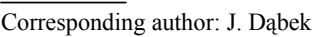

e-mail: dabek@tytan.umcs.lublin.pl

ISSN 1897-1695 (online) (C) 2007 GADAM Centre,

Institute of Physics, Silesian University of Technology.

All rights reserved. measured in 1947 (Naldrett and Libby, 1948).

A common opinion was expressed by geologists recently, that rhenium is a very dispersed element in some terrestial minerals, such as sulfides and oxides, and it does not form its own minerals. Recently, two new rhenium minerals have been discovered: rheniite $\left(\mathrm{ReS}_{2}\right)-$ which occurs in the crater zone of Kudriavy volcano, Kuril Islands, (Korzhinsky et al., 1994) and tarkianite $(\mathrm{Cu}, \mathrm{Fe})(\mathrm{Re}, \mathrm{Mo})_{4} \mathrm{~S}_{8}$ - found in central part of Finland (Kojonen et al., 2004). The first of them (rheniite) consists of $74.38 \% \mathrm{Re}$ and $25.62 \% \mathrm{~S}$, the second mineral (tarkianite) contains $53.61 \% \mathrm{Re}, 26.77 \% \mathrm{~S}, 12.32 \% \mathrm{Mo}$, $5.48 \% \mathrm{Cu}$ and $0.59 \% \mathrm{Fe}$. These minerals are so new that they are not yet listed in mineral catalogues. The abovementioned minerals are very rare, so molybdenite is the only useful ore of rhenium, with Re concentration up to $0.2 \%$. The metal is used in tungsten and molybdenum alloys in filaments of mass spectrometers, in medical instruments and as a catalyst in the chemical and petroleum industries. In the last years, Chile, Kazakhstan and United States (in descending order) provided most of the world's production of rhenium.

Osmium, the neighbour element of rhenium in the periodic table, in the natural state is a mixture of seven isotopes with the following abundances: ${ }^{184} \mathrm{Os}=0.023 \%$, ${ }^{186} \mathrm{Os}=1.600 \%,{ }^{187} \mathrm{Os}=1.510 \%,{ }^{188} \mathrm{Os}=13.286 \%$, ${ }^{189} \mathrm{Os}=16.251 \%,{ }^{190} \mathrm{Os}=26.369 \%$ and ${ }^{192} \mathrm{Os}=40.957 \%$ (Faure, 1986). Two of them take part in the natural radioactivity processes. ${ }^{186} \mathrm{Os}$ is produced from the isotope of platinum ${ }^{190} \mathrm{Pt}$ via alpha emission with a half-life $\mathrm{T}_{1 / 2}=4.9 \times 10^{11}$ years, and likewise ${ }^{186}$ Os decays to ${ }^{182} \mathrm{~W}$ 
( $\alpha$ decay) with $\mathrm{T}_{1 / 2}=2.0 \times 10^{15}$ years. Another isotope, ${ }^{187} \mathrm{Os}$, is formed by $\beta^{-}$decay of ${ }^{187} \mathrm{Re}$ and this pair of isotopes forms the physical basis of the Re-Os geochronology.

Because the maximum energy of $\beta$ particles emitted from ${ }^{187} \mathrm{Re}$ is extremely low at $2.65 \mathrm{keV}$, even compared with that of ${ }^{87} \mathrm{Rb}(275 \mathrm{keV})$, the measurement of the decay constant by direct counting method was very difficult (Dickin, 1995). A lately revised ${ }^{187} \mathrm{Re}$ decay constant of $1.666 \times 10^{-11} \mathrm{yr}^{-1}\left(\mathrm{~T}_{1 / 2}=4.16 \times 10^{10} \mathrm{yr}\right.$.) by Smoliar et al. (1996) provided a major improvement in the accuracy of Re-Os dating. The half-life of ${ }^{187} \mathrm{Re}$ is slightly shorter than ten times the age of the earth (Stein et al., 1998) and like other isotopic systems (U-Th- $\mathrm{Pb}, \mathrm{Rb}-\mathrm{Sr}$ and $\mathrm{K}-\mathrm{Ar}$ ) the Re-Os method can be used to date geologic events and it starts to play an important role in the geochronometry and mineral industry.

In this context, it is interesting to note that in the particular circumstances the $\beta$ - decay "constant" of a nuclide could be significantly modified. This case of $\beta^{-}$decay is named as bound-state beta decay as opposed to the usual continuum-state beta decay. In this case, the created electron will remain in a bound orbit of the daughter atom. The first theoretical description of this process was provided in 1947. The usual theory of bound-state beta decay for selected nuclides has been published by Bahcall (1961). In neutral atoms, inner orbits are fully occupied and bound-state beta decay is at least 100 -fold less probable than that to continuum-state beta decay. But in the case of highly-charged ions (all the electrons bound to the atom are removed), the probability of bound-state $\beta$-decay will drastically increase. Such experiment with bare ${ }^{187} \mathrm{Re}$ nuclides was performed by Bosch et al. in 1996. The half-life of ${ }^{187} \mathrm{Re}^{75+}$ was determined from the average of the two independent measurements as $\mathrm{T}_{1 / 2}=32.9 \pm 2 \mathrm{yr}$, being reduced by about nine orders of magnitude compared to the half-life of the neutral atoms (Bosch et al., 1996). Of course, the bound-state beta decay of ${ }^{187} \mathrm{Re}$ isotope in terrestrial conditions is quite negilible but in terms of stellar nucleosynthesis plays a significant role. The ${ }^{187} \mathrm{Re}-{ }^{187} \mathrm{Os}$ system has been proposed as one of the cosmological "clocks" to determine the lower limit of the age of the universe.

\section{THE RHENIUM-OSMIUM SYSTEM}

Rhenium and osmium belong to the rarest elements at the Earth's surface. Additionally, they behave differently when rocks melt and recrystallize. If there's no iron present, osmium has no preference between melts and solid minerals, but rhenium strongly favours the melt (Dickin, 1995). In consequence of this fractionation, rhenium is partioned from the mantle into the crustal system, whereas osmium is strongly held in the mantle ( $\mathrm{Re} / \mathrm{Os}_{\text {peridotite }}<<\mathrm{Re} / \mathrm{Os}_{\text {basalt }}$ ). These unique advantages of the Re-Os chronometer among the others long-lived isotopic systems mean that the Re-Os method has a great potential in geochronological studies of ore formation, magma genesis and mantle evolution (Chesley et al., 2004).
Many of the earliest applications of Re-Os isotopic system were devoted to dating iron meteorites and molybdenites $\left(\mathrm{MoS}_{2}\right)$ which have generally high Re and Os contents. Average concentrations of $\mathrm{Re}$ and $\mathrm{Os}$ in iron meteorites are $2.5 \mathrm{ppm}$ and $30 \mathrm{ppm}$, respectively. Rhenium concentration in molybdenite varies from a few ppm up to 0.2 percent (Faure, 1986). Molybdenites are ideally suited for analysis by the Re-Os method. The natural osmium content in this mineral is less than $0.2 \mathrm{ppm}$ and all Os measured in a molybdenite is radiogenic daughter ${ }^{187} \mathrm{Os}$, accumulated through the time by the decay of parent ${ }^{187} \mathrm{Re}$. In this case the age Equation (2.1) reduces to a short form (2.2) (Stein et al., 1998).

$$
\left[\frac{{ }^{187} \mathrm{Os}}{{ }^{188} \mathrm{Os}}\right]_{\text {present }}=\left[\frac{{ }^{187} \mathrm{Os}}{{ }^{188} \mathrm{Os}}\right]_{\text {initial }}+\left[\frac{{ }^{187} \mathrm{Re}}{{ }^{188} \mathrm{Os}}\right]_{\text {present }}\left(e^{\lambda t}-1\right)
$$

$$
\left[{ }^{187} \mathrm{Os}\right]_{\text {present }}=\left[{ }^{187} \mathrm{Re}\right]_{\text {present }}\left(e^{\lambda t}-1\right)
$$

Mass spectrometric analysis of Re and Os has long been recognized as an important goal in geochemistry. In the past, the Re-Os isotopic system was mainly analyzed by using secondary ion mass spectrometry (SIMS), resonance ionization mass spectrometry (RIMS), inductively coupled plasma mass spectrometry (ICPMS) and accelerator mass spectrometry (AMS). The high ionization potentials of Os $(8.7 \mathrm{eV})$ and $\mathrm{Re}(7.9 \mathrm{eV})$ have prevented the formation of positively charged metallic ions at typical temperatures attainable in thermal ionization mass spectrometry and they have also limited the sensitivity of SIMS measurements. In 1991, the first highly sensitive and effective determinations of Os and Re isotope ratios from $\mathrm{OsO}_{3}{ }^{-}$and $\mathrm{ReO}_{4}{ }^{-}$ions were reported (Creaser et al., 1991; Völkening et al., 1991). In these works published nearly simultaneously, a negative thermal ionization mass spectrometry (NTIMS) technique was applied as a highly sensitive method for the isotope ratio measurements of the transition metals in the form of oxide anions. This NTIMS method allows levels of precision over an order of magnitude better than the positive ion techniques described above. Since the introduction of NTIMS technique, Re-Os isotope analyses have become possible for many rocks and minerals (Pearson, 1999; Smith, 2003; Brandon and Walker, 2005).

At present, two techniques are most common in the analysis of Re and Os, namely the inductively coupled plasma mass spectrometry (ICPMS) and negative thermal ionization mass spectrometry (NTIMS). Of the two, the NTIMS provides a greater precision for measuring $\mathrm{Re}$ and Os isotopic ratios (Markey et al., 1998).

\section{PRINIPLES OF THERMAL IONIZATION}

Surface ionization, often termed thermal ionization or thermal ion emission, is the process by which a part of the material coated on (or directed onto) a heated metal surface evaporates in a negative or positive ionic state (Kawano and Page, 1983). Theoretical principles and instrumentation used for positive thermal ionization (PTI) and negative thermal ionization (NTI) are very similar. Conversion from positive thermal ionization mass spec- 
trometry (PTIMS) to negative thermal ionization mass spectrometry (NTIMS) can be easily achieved by reversing the polarity of the magnet and of the extraction plates in the ion source of a mass spectrometer (Hattori et al., 1988).

The positive ions emitted from heated metal filaments were used in the ion sources of the early mass analysis instruments. For example, the mass spectrometer constructed by Dempster in 1918 was equipped with an ion source comprising a single filament. This experimental set-up was used for the primary investigations of the surface ionization phenomenon. The first reliable identification of positive ions emitted from sodium halides deposited onto a platinum ribbon was made by Richardson in 1910. Also Richardson in 1912 found, that negative ions as well as electrons were emitted from alkaliearth iodides and bromides deposited on platinum ribbon heated to $600-700 \mathrm{~K}$. The masses of the obtained ions were about 120 and 88 amu., nearly corresponding to masses of $\mathrm{I}^{-}$and $\mathrm{Br}^{-}$, respectively (Kawano and Page, 1983). Since then the PTI and NTI phenomena have been investigated both experimentally and theoretically by many workers.

The ionization efficiencies, $\beta^{+}$and $\beta^{-}$for positive- or negative-ion production are commonly expressed by the Saha-Langmuir equation:

$$
\begin{aligned}
& \beta^{+}=\frac{N_{+}}{N_{0}+N_{+}}=\left\{1+\frac{g_{0}}{g_{+}} \exp \left[\frac{\mathrm{EI}-\Phi}{k \mathrm{~T}}\right]\right\}^{-1} \\
& \beta^{-}=\frac{N_{-}}{N_{0}+N_{-}}=\left\{1+\frac{g_{0}}{g_{-}} \exp \left[\frac{\Phi-\mathrm{EA}}{k \mathrm{~T}}\right]\right\}^{-1}
\end{aligned}
$$

where $\mathrm{N}_{0}, \mathrm{~N}_{+}$and $\mathrm{N}_{\text {. }}$ are the number of neutral atomic species, and positive and negative ions, respectively, evaporated from unit surface area per unit time; $g_{0}, g_{+}$and $\mathrm{g}$ - are the partition functions of the neutral species and positive and negative ions; EI is the first ionization energy of the investigated species; $\Phi$ is the electron work function of the filament material; EA is the electron affinity of the investigated species; $\mathrm{k}$ is the Boltzmann constant and $\mathrm{T}$ is the surface temperature of the filament.

These equations include the principal parameters for ionization, such as temperature and electron work function of the filament material. The higher yields of the PTI are obtained from surfaces of high value of $\Phi(\Phi>\mathrm{EI})$, and consequently, with a decrease in the work function $(E A>\Phi)$, the intensity of the NTI increases as well. Therefore, a filament material should be chosen from those metals which have a suitable high or low work function, high melting point and which are stable with respect to chemical reactions with the loaded sample. In the PTI technique, it is quite easy to attain efficiency $\beta^{+}$ close to $100 \%$ when a beam of alkali-metal atoms is directed onto $\mathrm{W}, \mathrm{Re}, \mathrm{Pt}$ or $\mathrm{O}=\mathrm{W}$ (oxidized tungsten) surfaces. In the NTI, on the other hand, the values of electron work functions of pure metals (see Table 1) are too high for sufficient generation of negative thermal ions. In this case, the electron work function of these materials can be drastically reduced by covering the filament or ribbon with a thin layer of, for example, $\mathrm{BaO}, \mathrm{La}_{2} \mathrm{O}_{3}$,
Table 1. Typical data of the effective mean work functions (Kawano, 2006).

\begin{tabular}{lccc}
\hline $\begin{array}{l}\text { Surface } \\
\text { material }\end{array}$ & $\begin{array}{c}\mathrm{T} \\
(\mathrm{K})\end{array}$ & $\begin{array}{c}\boldsymbol{\varphi}^{+} \\
(\mathrm{eV})\end{array}$ & $\begin{array}{c}\varphi^{\mathrm{e}} \\
(\mathrm{eV})\end{array}$ \\
\hline Tungsten & $2000-2200$ & $5.15 \pm 0.05$ & $4.59 \pm 0.01$ \\
Rhenium & $1900-2400$ & $5.37 \pm 0.10$ & $4.94 \pm 0.04$ \\
Platinum & $1200-1800$ & $5.61 \pm 0.13$ & $4.73 \pm 0.16$ \\
\hline
\end{tabular}

$\mathrm{Ba}\left(\mathrm{NO}_{3}\right)_{2}$ or $\mathrm{Ba}(\mathrm{OH})_{2}$ (Volkening et al., 1991; Suzuki et al., 2004).

However, it should be noted, that the work function listed in handbooks is usually the mean work function $\left(\varphi^{\mathrm{e}}\right)$ effective for electron emission from polycrystalline surfaces. Any polycrystalline surface (in contrast to monocrystalline surfaces) is generally heterogeneous in work function because it consists of many patchy faces with local work functions ranging from the minimum value $\left(\varphi_{\min }\right)$ to the maximum $\left(\varphi_{\max }\right)$. The negative ions and electrons are emitted predominantly from the faces with lower value of the work function. The efficiency of the negative ions production is especially high when the filament surface is uniformly covered by a homogeneous layer lowering the work function of the surface.

In a typical single-filament thermal ionization source a filament or ribbon serves as sample holder, heater and ionizer. For the ionized samples being ionized which are enough volatile, the use of a double-filament ion source with separated evaporation and ionization processes is crucial. Usually, the evaporator is maintained at a suitable lower temperature but the ionizing filament can be operated at higher temperatures, yielding higher ionization efficiencies without rapid loss of the sample. The advantages of such source arrangement are threefold: (1) because the evaporation and the ionization processes can be controlled separately, a smaller amount of a sample is required; (2) since the ionization parameters are more stable, a higher precision of measurements can be obtained; (3) separately heated evaporation and ionization filaments make it possible to reduce the so-called 'memory effect'.

It is generally accepted that NTI method is useful in producing negative ions from those atoms and molecules whose electron affinity (EA) is larger than $1 \mathrm{eV}$ (Kawano and Page, 1983). Under sophisticated experimental conditions, however, this method of negative ionization seems to be applicable even to species having an electron affinity of $0.5 \mathrm{eV}$. To the best knowledge of the authors, the electron affinity values for the different rhenium and osmium oxides are not determined, but, as can be seen from several papers, the EA are sufficiently high to obtain the ion currents of $\mathrm{ReO}_{4}^{-}$and $\mathrm{OsO}_{3}{ }^{-}$ions with intensities of range $10^{-11}-10^{-12} \mathrm{~A}$.

\section{THE MASS SPECTROMETER}

In our laboratory we have a conventional, single focussing magnetic sector field mass spectrometer, type MI 1201, which will be adapted to determine rhenium and osmium isotope concentrations using negative thermal ion source. This mass spectrometer, shown in Fig. 1, is 


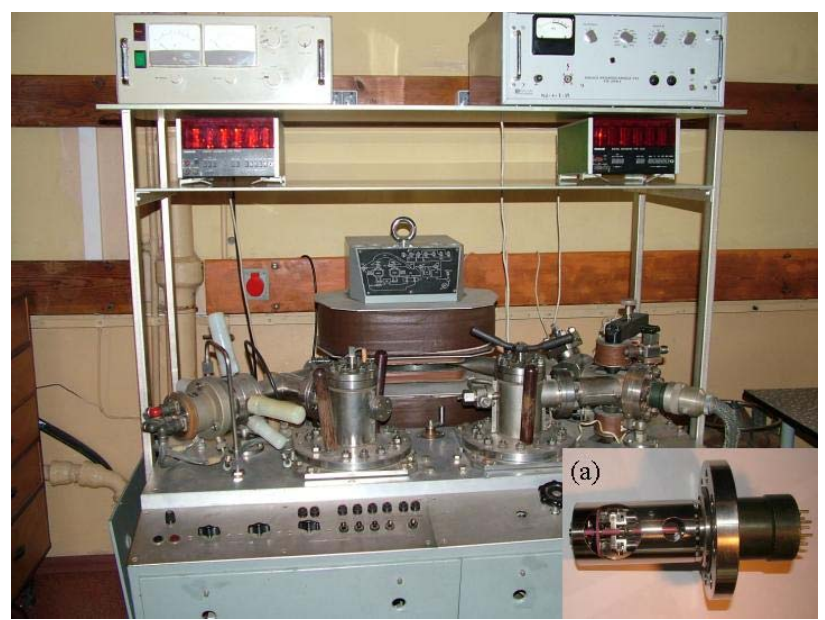

Fig. 1. The mass spectrometer; (a) thermoemision ion source.

capable to perform analyses in the mass range of $1-600$ amu., with the mass resolution $\mathrm{M} / \Delta \mathrm{M} \approx 1100$. The nominal accelerating voltage is set at $5.6 \mathrm{kV}$, and the mass spectrum is measured by varying the field strength of the electromagnet. The apparatus is equipped with an ion collector with three Faraday cups and with a triple filament thermoemission ion source. This type of source is very suitable because it enables independent temperature control on the filaments on which the evaporation and ionization of sample proceeds. A simple voltage stabilizer using 4-wire approach to control the filament temperature was described by Halas et al. (2002). The temperature controller mentioned above was successfully applied for analysis of potassium concentration by the isotope dilution method and is planned to be used for the measurements of the Re-Os isotopic system.

\section{SUMMARY}

The rhenium-osmium isotopic system provides one of the newest methods for radiometric dating in cosmo- and geochronology. The earliest applications of Re-Os chronometer were adapted to dating the iron meteorites to determine the age of our solar system. Moreover, it was realized that molibdenites $\left(\mathrm{MoS}_{2}\right)$ show a unique usability for the Re-Os dating because they are associated with copper sulphide minerals and tend to have particularly high Re concentration. At the beginning, the possibility to obtain highly precise and accurate Re-Os ages of geologic materials was limited by the two difficulties: (1) lack of sensitive mass spectrometry techniques, and (2) uncertainty in the value of ${ }^{187} \mathrm{Re}$ decay constant. The use of negative thermal ionization method was essential for the production of the ion beams of the negatively charged oxides $\left(\mathrm{OsO}_{3}^{-}, \mathrm{ReO}_{4}^{-}\right)$. Such analytical improvement has opened a wide field of applications of isotopic Re-Os method to analyses of Re and Os concentrations in geological samples. The Re-Os system is the only system that can be directly applied to date mineralization of sulphides and oxides and has enormous potential in mineral exploration.

\section{REFERENCES}

Bahcall JN, 1961. Theory of Bound-State Beta Decay. Physical Review 124: 495-499.

Bosch F, Faestermann T, Friese J, Heine F, Kienle P, Wefers E, Zeitelhack K, Beckert K, Franzke B, Klepper O, Kozhuharov C, Menzel G, MoshammerR, Nolden F, Reich H, Schlitt B, Steck M, Stöhlker T, Winkler T and Takahashi K, 1996. Observation of Bound-State $\beta^{-}$Decay of Fully Ionized ${ }^{187} \mathrm{Re}:{ }^{187} \mathrm{Re}-{ }^{187}$ Os Cosmochronometry. Physical Review Letters 77: 5190-5193.

Brandon AD and Walker RJ, 2005. The debate over core-mantle interaction. Earth and Planetary Science Letters 232: 211-225.

Chesley J, Righter K and Ruiz J, 2004. Large-scale mantle metasomatism: a Re-Os perspective. Earth and Planetary Science Letters 219: 49-60.

Creaser RA, Papanastassiou DA and Wasserburg GJ, 1991. Negative thermal ion mass spectrometry of osmium, rhenium and iridium. Geochimica and Cosmochimica Acta 55: 397-401.

Dickin AP, 1995. Radiogenic Isotope Geology. Cambridge University Press: 204 pp.

Faure G, 1986. Principles of Isotopic Geology. John Wiley and Soons, New York: 6,265 pp.

Hałas S, Wójtowicz A, Nowak J and Durakiewicz T, 2002. Temperature controller for thermal ionization mass spectrometer. Rapid communications in mass spectrometry 16: 77-80.

Hattori K, Cole TJS and Menagh DP, 1988. Negative ionization processes of osmium for isotopic measurements. International Journal of Mass Spectrometry 176: 189-201.

Kawano H, 2006. Mean work functions effective for negative ionic, electronic and positive ionic emission from polycrystalline surfaces. Applied surface science 252: 5233-5242.

Kawano H and Page FM, 1983. Fundamental Aspects of Surface Ionization. International Journal of Mass Spectrometry and Ion Physics 50: 1-33.

Kojonen KK, Roberts AC, Isomaki OP, Knauf VV, Johanson B and Pakkanen L, 2004. Tarkianite, $(\mathrm{Cu}, \mathrm{Fe})(\mathrm{Re}, \mathrm{Mo})_{4} \mathrm{~S}_{8}$, a new mineral species from the Hitura Mine, Nivala, Finland. The Canadian Mineralogist 42: 539-544.

Korzhinsky MA, Tkachenko SI, Shmulovich KI, Taran YA and Steinberg GS, 1994. Discovery of a pure rhenium mineral at Kudriavy volcano. Nature 369: 51-52.

Markey R, Stein H and Morgan J, 1998. Highly precise Re-Os dating for molybdenite using alkaline fusion and NTIMS. Talanta 45: 935-946.

Naldrett SN and Libby WF, 1948. Natural Radioactivity of Rhenium. Physical Review 73: 487-493.

Pearson DG, 1999. The age of continental roots. Lithos 48: 171-194.

Smith AD, 2003. Critical evaluation of Re-Os and Pt-Os isotopic evidence on the origin of intraplate volkanism. Journal of Geodynamics 36: 469-484.

Smoliar MJ, Walker RJ and Morgan WJ, 1996. Re-Os ages of group IIA, IIIA, IVA and IVB meteorites. Science 271: 1099-1102.

Stein HJ, Morgan WJ, Markey J and Hannah JL, 1998. An introduction to Re-Os. What's in it for the mineral industry? SEG Newsletters 32: 7-15.

Suzuki K, Miyata Y and Kanazawa N, 2004. Precise Re isotope ratio measurements by negative thermal ionization mass spectrometry (NTI-MS) using total evaporation technique. International Journal of Mass Spectrometry 235: 97-101.

Völkening J, Walczyk T and Heumann KG, 1991. Osmium isotope ratio determination by negative thermal ionization mass spectrometry. International Journal of Mass Spectrometry and Ion Processes 105: 147-159. 